\title{
LÍNGUA PORTUGUESA E O PROCESSO FORMATIVO DOS SUJEITOS
}

\author{
PORTUGUESE LANGUAGE AND THE SUBJECTS' TRAINING PROCESS
}

\section{Denise da Costa Dias Scheffer}

Universidade de Cruz Alta, Cruz Alta, RS, Brasil. E-mail: dcdscheffer@gmail.com

\section{Dieison Prestes da Silveira}

Universidade Federal do Paraná, Curitiba, PR, Brasil. E-mail: dieisonprestes@gmail.com

\section{Camila Baratto Bataglin}

Universidade Regional do Noroeste do Estado do Rio Grande do Sul, Ijuí, RS, Brasil. E-mail: camilabarattobataglin@gmail.com

\section{Carine de Fátima Ribeiro Hinnab}

Universidade de Cruz Alta, Cruz Alta, RS, Brasil. E-mail: cfrhinnah@gmail.com

\section{Ciro Portella Cardoso}

Universidade de Cruz Alta, Cruz Alta, RS, Brasil. E-mail: ciro.cardoso@hotmail.com

Resumo: O objetivo do artigo é analisar a língua portuguesa no processo de formação dos su-jeitos em suas interaçôes interpessoais, a partir da comunicabilidade naturalmente exercida no campo social, e posterirormente aprimorada pela técnica da fala, da leitura e da escrita, construindo dessa forma, o caminho formativo nas relaçóes coletivas. Para o referenciamen-to do estudo, percorre-se o caminho metodológico da pesquisa bibliográfica, de natureza qualitativa, para um levantamento doutrinário pelo viés educativo da língua portuguesa e suas interseçóes sociais na coletividade.

Palavras-chave: Sujeito. Aprendizagem. Formação.

Abstract: The objective of the article is to analyze the Portuguese language in the process of formation of the subjects in their interpersonal interactions, from the communicability natu-rally exercised in the social field, and later improved by the technique of speaking, reading and writing, thus building the path formative in collective relationships. For the reference of the study, the methodological path of bibliographic research, of a qualitative nature, is cov-ered for a doctrinal survey through the educational bias of the Portuguese language and its social intersections in the community.

Keywords: Subject. Learning. Training. 


\section{Introdução}

língua portuguesa manifesta-se incialmente aos sujeitos enquanto comunicação

Latravés da fala, ensinada já na primeira infância, no grupo familiar. Direcionada sequencialmente às atividades escolares, no campo da educação, segue a partir da alfabetização, já que, o uso da língua escrita perfaz a simbologia denominada letras do alfabeto. É importante ressaltar que o artigo abordará o contexto histórico da língua portuguesa no Brasil, sua importância enquanto embasamento prático de comunicação (escrita e falada) e sua atuação no processo de formação dos sujeitos para a vida em sociedade.

A língua portuguesa constitui-se como base formativa dos sujeitos, promovendo seu desenvolvimento no processo comunicativo dos mesmos. O seu posicionamento é consolidado no país acerca de conceitos históricos, oriundos da colonização portuguesa, sendo fixada sua competência enquanto língua materna.

Obstante ressaltar que a fundamentação teórica é explanada com base na obra de Vygotsky, citando, por exemplo, Educação Social da Mente (1989) e ainda Paulo Freire, que traz a educaçáo como liberdade aos sujeitos. $\mathrm{O}$ artigo reflete a contemporaneidade, através de seus resultados e discussóes, com o olhar voltado para os livros Educação como Prática da Liberdade (1967) e Pedagogia da Autonomia (1996).

O objetivo do artigo é analisar a língua portuguesa no processo de formação dos sujeitos em interaçóes interpessoais, percorrendo o caminho metodológico da pesquisa bibliográfica, de natureza qualitativa. De acordo com Marconi e Lakatos (2004, p. 269), "a metodologia qualitativa preocupa-se em analisar e interpretar aspectos mais profundos, descrevendo a complexidade do comportamento humano" acerca do método de coleta de dados, profere-se o estudo em referências bibliográficas como metodologia de estudo e pesquisa, para a temática estudo abordada.

\section{A língua portuguesa e seu aprendizado no campo da linguagem}

A sequência do trabalho se dá de modo objetivo acerca do roteiro direcionado ao embasamento histórico da língua portuguesa, a importância do aprendizado, do uso da língua, suas concepçôes e utilização de forma escrita e falada, para a construção do conhecimento, como explica Pereira et al. (2018, p. 13), "o conhecimento pode ser adquirido de diversas formas: sensação, percepção, imaginação, memória, linguagem, raciocínio e intuição”.

Tendo em vista a comunicação interpessoal dos indivíduos, relacionadas a fala e a escrita dos sujeitos, em sua base de aprendizagem, vincula-se com as exposiçóes históricas da língua portuguesa e integram o direcionamento da educação no país, através das prepositivas de ensino e aprendizagem, acerca da história da língua, segundo Assis, "a história de uma língua está ligada a história do seu povo, aos acontecimentos de natureza política e social”. (2016, p. 04)

Sobre o ato de comunicação, encontra-se vinculado as condiçôes enunciativas de regulação de toda troca de comunicação a partir da linguagem, como descreve (Charaudeau, 1992):

Todo ato de comunicação se inscreve em uma situação pré-estruturada, definida pelas respostas a questóes como: do que se fala? Com quem se fala? Para que se fala? Através do que se fala? Como se fala? Ao comunicar, os sujeitos envolvidos devem se submeter à existência destas condições enunciativas particulares a cada situação 
de comunicação. Esses sujeitos devem se reconhecer semelhantes, por estarem conscientes destas condiçóes, por suporem que possuem um certo conhecimento mútuo sobre o que é dito, e sobre os valores e as normas sociais. Os sujeitos se reconhecem num processo colaborativo de construção de sentido, entendido como "co-intencionalidade" ou "princípio de responsabilidade mútua".

Tendo em vista a colonização portuguesa no Brasil, a língua sofreu diversas variações miscigenadas sob o impacto das diferentes culturas. Cabe destacar que a presença dos índios que aqui viviam e sua língua materna indígena, juntamente a nova língua portuguesa trazida pelos colonizadores, também se fizeram fator de construção para o uso contemporâneo da língua portuguesa.

Com relação à língua materna, Araújo e Freitas descrevem:

Em se tratando do ensino de língua portuguesa, verificamos, ainda, uma forte tradição da formação para os conteúdos em si mesmo, geralmente, por métodos transmissivos, de memorização de regras, pelo ensino convencional de gramática, baseado em exercícios que não visam à formação com vistas a "saber fazer" e "saber refletir", muito menos a ampliação da competência discursiva e das práticas de letramento nos alunos. (2006, p.3)

Entende-se que a iniciação da linguagem se dá pela comunicação verbal, a língua falada, para posteriormente a transição para a escrita, "aliando ambos componentes no aprendizado da língua portuguesa, dessa forma, ocorre juntamente as relaçôes comunicativas e formativas do convívio social dos sujeitos”, como afirma Vygotsky ([1929] 2000). Essas relaçôes sociais são fundantes do sujeito, e ainda em suas palavras, a formação do eu só ocorre mediante a interação com o outro.

Em conceituação crítica reflexiva acerca da língua, pertinente destacar o autor Ferdinand Saussure. Suas concepçóes permitiram inovaçóes no campo científico em estudos voltados a língua e a linguagem, e assim, segundo Saussure (2006, p. 45), "a linguagem comporta duas partes, uma tem por objeto a língua (langue) e outra, a fala (parole)", mencionando ainda que a primeira se trata da essência do social e a segunda como uma parte individual da linguagem.

Em visão moderna, o autor reflete acerca da língua enquanto relaçôes individuais tratadas em conjunto por meio da comunicação, denominando elementos que promovem o discurso, ou gêneros discursivos. Segundo Bakhtin (1997b, p. 279), "qualquer enunciado considerado isoladamente é, claro, individual, mas cada esfera de utilização da língua elabora seus tipos

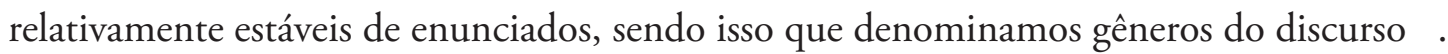

A conceituação histórica e basilar da língua e seu desenvolver do componente linguagem, perfaz o desenvolvimento de estudo da temática dos gêneros discursivos, do uso da linguagem em sus variaçóes, remetendo a busca do aprofundamento do uso da língua falada e escrita no processo formativo dos sujeitos, cujo percorre a narrativa de aprendizado da língua portuguesa no campo escolar, através dos preceitos pedagógicos de ensino.

A emancipação dos sujeitos se dá no processo de ensino e aprendizagem referido pela escola, no aprimoramento das relaçóes comunicativas e evidencias através do uso da língua e das ramificaçôes da linguagem, segundo Vygotsky (1989), "o aprender é um processo mediado, individual e coletivo, que faz despertar processos internos de desenvolvimento".

Os sujeitos, enquanto escolares, vislumbram o aprendizado de conteúdos normatizados legalmente, com diretrizes acerca da abordagem de aprendizagem definida previamente, dividindo 
o ensino escolar em níveis, da educação básica, referenciando o que se aprende e quando, de acordo com elementos cognitivos, de idade e desenvolvimento intelectual.

A prática de leitura e escrita, se dá como técnica de ensino e aprendizagem escolar, denominadas a partir da língua materna portuguesa no país, na concepção normativa legal percebida na legislação inerente ao âmbito escolar, visando o desenvolvimento, como se relata:

$\mathrm{O}$ conhecimento aprendido na escola pode não ter uma aplicabilidade imediata na vida cotidiana, mas a importância de aprender a ler e escrever vai ser percebida pelos alunos se eles sentirem que os conceitos escolares e o processo de construção desses conceitos são pertinentes para o seu desenvolvimento global. E será por essa via - a do desenvolvimento do sujeito - que o aprendizado da leitura e da escrita poderá atingir a vida prática do aluno, na medida em que a forma pela qual ele percebe o cotidiano vai sendo afetada pelo desenvolvimento promovido pelas aprendizagens escolares. (LIMA, 1997).

A escrita está interligada a prática da leitura, a partir de experiências adquiridas em diversas metodologias de aprendizagem A leitura é a forma de aprimoramento da escrita, também para exercício da memória e do conhecimento sobre os mais variados assuntos no campo do conhecimento. A diversas maneiras de escrita e leitura, peritem as interaçóes das relaçóes entre os sujeitos, para comunicação e emancipação das relaçôes sociais coletivas.

Sobre a relaçấo da escrita e da leitura, destaca-se o exposto por Antunes (2003, p. 54):

Através da leitura se consegue mais eficácia no desenvolvimento sistemático da linguagem e da personalidade. Portanto, [...] elaborar um texto é uma tarefa cujo sucesso não se completa, simplesmente, pela codificação das ideias ou das informaçôes, através de sinais gráficos. Ou seja, produzir um texto não é uma tarefa que implica apenas o ato de escrever. Não começa, portanto, quando tomamos nas mãos papel e lápis. Supóe, ao contrário, várias etapas, interdependentes e intercomplementares, que vão desde o planejamento, passando pela escrita propriamente, até o momento posterior da revisão e da escrita.

A leitura e a escrita são ferramentas didáticas do ensino e aprendizado da língua portuguesa. O abito de ler é estimulado na educação básica, para através da leitura os sujeitos partilhem suas experiencias. Dessa forma, importante é o papel do professor de Língua Portuguesa (LP) deve, "recuperar na escola e trazer para dentro dela o que dela se exclui por princípio - o prazer - me parece o ponto básico para o sucesso de qualquer esforço honesto de "incentivar a leitura". (GERALDI, 1984, p. 32).

O professor, no papel de mediador do conhecimento, perfaz a jornada do ensinar seus alunos para as vivencias dentro e fora da escola. $\mathrm{O}$ aluno deve desenvolver sua percepção a partir da leitura e da escrita, observando dessa forma a sua visáo de mundo, o coletivo, as relaçóes sociais, culturais, familiares e profissionais. Qualquer texto reforça ideias já sedimentadas ou propóe visóes novas. (ANTUNES, 2003, p. 81).

Ressalta-se ainda a importância do trabalho pedagogico de aprendizagem, como encontrase no Guia de Estudos do Projeto Veredas - Formação Superior de Professores (2202, vol2, módulo 1, p.155), por exemplo, a seguinte explanação:

Educar é aperfeiçoar a capacidade de audição e de fazer silêncio - esse é um desafio inicial. A escola é o lugar privilegiado para a aprendizagem, para a elaboração individual e coletiva do conhecimento. Por isso é preciso que os alunos desenvolvam a capacidade de expressar suas ideias e aprendam a fazer 
silêncio para ouvir. É preciso criar o hábito de falar baixo, evitando o barulho que possa perturbar a fala, as perguntas a serem feitas, as respostas a serem dadas, as explicaçóes do professor, os estudos, a realização ou apresentação de trabalhos, individual ou em grupo, e qualquer tipo de atividade intelectual. Trata-se de desenvolver o hábito de um silêncio intencional, uma atitude consciente, fundada no respeito ao outro e na cooperação. Ao desenvolvê-lo, a sala de aula e toda a escola transforma-se em um ambiente que facilita a interação professor/aluno, o desenvolvimento do pensamento e da linguagem e a elaboração coletiva do conhecimento.

Pertinente destacar as diretrizes da educação partilham de critérios teóricos e práticos na didática de ensino e aprendizagem, portanto, acerca da legislação norteadora do sistema educacional brasileiro, a denominada Lei das Diretrizes e Bases da Educação Brasileira - LDB - de 1996, elenca matrizes curriculares primordial de aprendizado, baseado em áreas de ensino, tendo como ponto inicial, a alfabetização dos educandos, suas interaçôes sociais e culturas no meio escolar e sua inserção no contexto de ensino, nas relaçôes de comunicação, na busca do acolhimento dos sujeitos, promovendo a emancipação para a cidadania e o mercado de trabalho.

Os resultados da presente pesquisa orientam a construção de uma trajetória acerca do ensino e aprendizado da língua portuguesa, aliada ao processo formativo dos sujeitos para a vida em sociedade, suas relaçóes interpessoais na coletividade, conforme demonstrado na imagem abaixo:

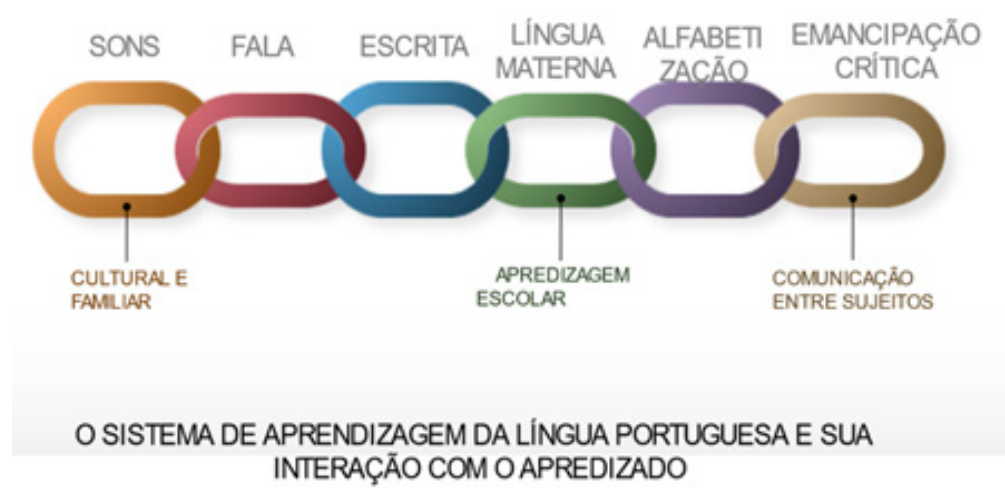

A pesquisa, embasada nas referências bibliográficas, demonstra uma trajetória de aprendizagem cognitiva, acerca da simbologia tradicional e cultural de ensino e aprendizagem. A mesma é voltada à língua portuguesa enquanto referência de fala e escrita e a alfabetização se dá como normalizadora das informaçôes e do uso comunicativo e interativo da língua nas relaçôes entre os sujeitos.

Alíngua portuguesa enquanto ferramenta de comunicação e interações no meio educacional integra-se ao ambiente social formativo dos sujeitos, uma vez que provoca aproximação entre grupos, através das interaçôes visuais e linguísticas de aproximação; tendo como base a língua portuguesa com enfoque educacional emancipatório dos educandos, pautadas na sua formação cidadã. De acordo com Paulo Freire $(1967$, p. 2), "as palavras não podem ser ocas, pois elas verbalizam o pensamento".

Acerca do uso ainda linguagem em palavras, Freire descreve:

São as palavras geradoras, a partir de cuja discussão o alfabetismo irá tomando posse de seu idioma. Falamos de discussão, e este é um ponto capital para o 
aprendizado, pois segundo esta pedagogia a palavra jamais pode ser vista como um "dado" (ou como uma doação do educador ao educando) mas é sempre, e essencialmente, um tema de debate para todos os participantes do círculo de cultura. $(1967$, p. 4).

$\mathrm{O}$ ensino da linguagem permeia o tradicionalismo da aprendizagem, acerca da simbologia do letramento e base para a alfabetização escolar, Vygotsky (1989, p.70), afirma que, "diferentemente do ensino da linguagem falada, no qual a criança pode se desenvolver por si mesma, o ensino da linguagem escrita depende de um treinamento artificial”. Ocorrendo, portanto, a transmissão de saberes pela repetição de manobras, estas integradas a bagagem individual que cada educando traz de sua realidade, mas interligado ao mesmo método de ensino e aprendizagem escolar.

Ainda sobre a transmissão dos saberes, Vygotsky explica:

Os educadores devem organizar todas essas açóes e todo o complexo processo de transição de um tipo de linguagem escrita para outro. Devem acompanhar esse processo através de seus momentos críticos, até o ponto da descoberta de que se pode desenhar não somente objetos, mas também a fala. Se quiséssemos resumir todas essas demandas práticas e expressá-las de uma forma unificada, poderíamos dizer que o que se deve fazer é ensinar às crianças a linguagem escrita, e não apenas a escrita de letras. (1989, p. 79)

Desta forma, a educaçáo promove a liberdade dos sujeitos diante de seu aprendizado da língua materna, para sua emancipação individual, enquanto vida em sociedade, tendo plena capacidade de interação no campo da linguagem falada e escrita, atribuída a comunicação entre os sujeitos e o fortalecimento de vínculos na promoção da língua portuguesa. Ainda nas palavras de Freire (1967, p. 7), "acerca da aprendizagem da língua materna, onde a aprendizagem é de interesse central é o debate da linguagem no contexto de uma prática social livre e crítica”.

Contudo, tem-se ainda a importancia da escola no porcesso de ensino e apredizagem da línga portguesa, em metodos de leitura e escrita para desenvolvimento e emancipaçao dos sujeitos, como descreve Soares (2002, p. 6):

É obrigação da escola, dar amplo e irrestrito acesso ao mundo da leitura, e isto inclui a leitura informativa, mas também a leitura literária: a leitura para fins pragmáticos, mas também a leitura de fruição: a leitura que situaçôes da vida real exigem, mas também a leitura que nos permita escapar por alguns momentos da vida real.

Seguindo o que discorre Freire (1996, p. 25), "educar não é apenas transferir o conhecimento", mas sim provocar a busca permanente da interação entre os sujeitos, em seu meio social, respeitando a realidade de cada um, mas promovendo a comunicação intempestiva da língua materna e sua consolidação nas relaçóes humanas, essas oriundas do contexto familiar, atendendo preceitos culturais, passados ao aprendizado da fala e da escrita, posteriormente a alfabetização e o aprendizado interdisciplinar, promovendo a liberdade de saberes e a comunicação interativa entre os sujeitos.

\section{Consideraçôes finais}

Na contemporaneidade, o processo formativo dos sujeitos e as relaçóes no campo social são refletidas nos mais variados contextos: sociais, culturais, educacionais e profissionais, sendo 
igualmente objeto de desenvolvimento de estudos acerca da temática. As relaçóes interpessoais evidenciadas a partir da comunicação pela língua portuguesa enfatizam a construção do desenvolvimento social e das práticas diversas entre os sujeitos.

O ensino e a aprendizagem da língua portuguesa fazem parte do campo formativo dos sujeitos, sendo enfatizados já no contexto familiar, nas primeiras interaçôes, passando pela construção da leitura e escrita, para o aprimoramento das técnicas comunicativas para as relaçóes sociais, políticas e econômicas, no capo da coletividade.

Destaca-se, portanto, o desenvolvimento do estudo da língua portuguesa para formação dos sujeitos, a narrativa constitutiva da linguagem para as relaçôes interpessoais dos mesmos, utilizando-se da comunicabilidade a partir da língua materna no campo social para o ensino e aprendizagem. Isto tudo permitiu o desenvolver do objetivo do presente estudo em analisar a língua portuguesa no processo de formação dos sujeitos com relação às interaçoóes comunicativas na coletividade e finalizando com referências ao enlace nas relaçôes de comunicação, acerca da formação dos sujeitos enquanto (con) vivências na vida em sociedade.

\section{Referências}

ANTUNES, I. Aula de português: encontro e interação. São Paulo: Parábola Editorial, 2003.

ARAÚJO, D. S. de, FREITAS, Silvane Aparecida de. O ensino de língua materna e a identidade do professor: uma perspectiva discursiva. Disponível em: file://C:/Users/dcdsc/ OneDrive/\%C3\%81 rea\%20de\%20Trabalho/ARTIGO\%20LETRAS/O\%20ensino\%20 de\%201\%C3\%ADngua\%20materna\%20-\%20DIRLENE.pdf. Acesso em outubro de 2021.

ASSIS, M. C.. História do Português Brasileiro, Vol. VII. Ed. Contexto: São Paulo, 2016. BRASIL. LDB - Lei de Diretrizes e Bases da Educacional. Lei 9394/96.

CHARAUDEAU, P. Grammaire du sens et de l'expression. Paris: Hachette, 1992.

FREIRE, Paulo. Pedagogia da autonomia. Ed. Paz e Terra, São Paulo: 1996.

FREIRE, Paulo. Educaçáo como prática da liberdade. Ed. Paz e Terra. Rio de Janeiro: 1967.

GERALDI, J. W. Práticas da Leitura de Textos na Escola. Revista Leitura: Teoria e Prática, ano 3, no 3, p. 25-33, Rio Grande do Sul, 1984.

LIMA, Elvira Souza. Desenvolvimento e aprendizagem na escola: aspectos culturais, neurológicos e psicológicos. São Paulo: GEDH - Grupo de Estudos do Desenvolvimento Humano, 1997.

MARCONI, M. de A.; Lakatos, E. M. (2004). Metodologia científica. São Paulo: Editora Atlas.

PEREIRA, A. S.; Shitsuka, D. M.; Parreira, F. J.; Shitsuka, R. Metodologia da pesquisa científica. $1^{\mathrm{a}}$ ed. UAB/NTE/UFSM. Universidade Federal de Santa Maria: Santa Maria, 2018.

SAUSSURE, F. de. Curso de linguística geral. Tradução de Antônio Chelini, José Paulo Paes e Isidoro Blikstein. 28 ed. São Paulo: Cultrix, 2006. 
SECRETARIA DO ESTADO DA EDUCAÇÃO DE MINAS GERAIS. Guia de Estudos. Coleção Veredas/ Formação Superior de Professores. BH: 2002, módulo 1, vol. 2.

SOARES, M. Alfabetização e Letramento. São Paulo: Contexto, 2002.

VYGOTSKY, L. S. Manuscrito de 1929. Educação \& Sociedade, ano XXI, no 71, p. 21-44, julho/2000.

VYGOTSKY, Lev S. A formaçáo social da mente: o desenvolvimento dos processos psicológicos superiores. São Paulo: Martins Fontes, 1989. 